\title{
Hyponatraemia in Acute Confusional States and Coma
}

\author{
KAZAL KANTI DAN, ${ }^{1}$ GOUTAM KUMAR ACHERJYA, ${ }^{2}$ MOSTOFA KAMAL CHOWDHURY, ${ }^{3}$ PARITOSH KUMAR BARAL, ${ }^{4}$ \\ MD. TITU MIAH ${ }^{5}$
}

\begin{abstract}
:
Background: Though hyponatraemia is a common scenario in our daily clinical practice, the mortality and morbidity are very high without early detection and prompt treatment. Both under and over treatment of hyponatraemia may cause permanent brain damage. Proper and meticulous treatment may prevent development of permanent brain disorder. So, a study was carried out to see the prevalence of hyponatraemia in acute confusional states and coma. The effect of hyponatraemia on consciousness level was also observed.
\end{abstract}

Materials \& Methods: A cross sectional study.

Results: $A$ total number of sixty (60) cases with acute confusional state and coma were recruited in our study. Among 60 patients with acute confusional states including coma, 85\% (5I) patients were presented with hyponatraemia. In the study, mild, moderate and severe hyponatraemia were $20 \%, 13.33 \%$ and $51.67 \%$ respectively. Of the total study population, $31.67 \%, 33.33 \%$ and $35 \%$ presented with coma, stupor and drowsiness respectively. Severe hyponatraemia was found in $68.42 \%$ in comatose, $50 \%$ in stuporous and $38.1 \%$ in drowsy patients. $47.06 \%$ of hyponatraemic patients were noticed in several intracranial disorders. Hepatic encephalopathy, gastrointestinal disorders, chronic renal failure and ischemic heart disease comprised 13.73\%, II.76\%, 9.80\% and 5.89\% respectively. Diabetic ketoacidosis and hypoglycaemic shock comprised 3. $92 \%$ each and congestive heart failure and acute respiratory distress syndrome comprised $1.96 \%$ each of hyponatraemic patients.

Conclusions: Hyponatraemia is a common clinical problem in our day to day clinical practice. If neglected this may result in permanent brain malfunction which may be prevented with earlier detection and correction under meticulous supervision.

Keywords: Hyponatraemia, Acute confusional states, Coma.

DOI: http://dx.doi.org//0.3329/jom.v19i2.37230

\section{Introduction:}

Hyponatraemia can be defined as a plasma sodium concentration below normal range (136-144 mmol/L). ${ }^{1}$ It has been detected as the most frequent electrolyte disorder in clinical medicine., ${ }^{2,3}$ Mild hyponatraemia is seldom associated with any specific features and symptoms usually relate to the underlying cause of the hyponatraemia. Severity of

1. Assistant Professor, Dept. of Cardiology, Jessore Medical College, Jessore.

2. Junior Consultant (Medicine), Upazila Health Complex, Bagherpara, Jessore.

3. Assistant Registrar, Dept. of Endocrinology, Dhaka Medical College Hospital, Dhaka.

4. Professor \& Head, Dept. of Medicine, Sikder Womens' Medical College, Dhaka.

5. Professor, Dept. of Medicine, Dhaka Medical College Hospital, Dhaka.

Corresponding author: Dr. Kazal Kanti Dan. Assistant Professor, Dept. of Cardiology, Jessore Medical College, Jessore. E-Mail: Kazal_Dan@Yahoo.Com.

Received: 06 February 2018;

Accepted: 04, May 2018 symptoms depends on rate of fall of plasma sodium concentration as well as absolute value. ${ }^{1}$ A patient with hyponatraemia may present with clouding of consciousness including coma, long track signs (including hemiparesis), seizures, hallucinations, tremor and intellectual impairment without clouding of consciousness and acute psychosis. ${ }^{4}$ Hyonatraemia is clinical manifestation of a wide variety of diseases, the most common of which are those of the gastrointestinal system. ${ }^{5}$ Others include intracranial diseases, especially after a subarachnoid haemorrhage.,7 Early detection and correction of hyponatraemia is an important step to reduce the morbidity and mortality in these diseases. ${ }^{8} \mathrm{~A}$ lot of studies on this problem has been carried out in many parts of the world. In Bangladesh, many a cases of hyponatraemia are being detected, particularly in acute confusional states and coma. So, an observational study on the problem can be emphasized.

\section{Materials \& Methods:}

This cross sectional study was done in the department of Medicine of Sir Salimullah Medical College Mitford Hospital 
(SSMCMH), Dhaka. A total number of sixty (60) cases with acute confusional state and coma were studied from October 2015 to December 2015. After random selection of the cases, detailed history and physical examination were carried out according to a data sheet. Serum electrolytes were estimated in all the cases. For this purpose, venous blood sample was taken during first presentation of the case before starting intravenous fluids. Other investigations were done according to the necessity of individual cases. All data were entered into a data sheet and were expressed in frequency and percentage as applicable. Data were entered in a main frame computer and were analyzed by percentage calculation. The inability to maintain a coherent sequence of thoughts accompanied usually by inattention and disorientation was taken as confusion. Drowsiness was defined as a disorder that simulates light sleep from which the patients can be easily aroused by touch or noise and maintain alertness for some time. Stupor was defined as a state in which the patient can be awakened only by vigorous stimuli. Deep unconscious state from which the patient could not be aroused was entitled as coma. Patients with prior resuscitation by intravenous fluids were not included in this study.

\section{Results:}

The prevalence of hyponatraemia is quite common in patients with acute confusional states and coma. In this study, out of 60 patients with acute confusional states including coma, 51 $(85 \%)$ presented with hyponatraemnia. Of these, 20 percent had mild hyponatraemia ( $\mathrm{pNa} 130-135.9 \mathrm{mmol} / \mathrm{L}$ ), 13.33 percent moderate $\left({ }_{\mathrm{p}} \mathrm{Na} 125-129.9 \mathrm{mmol} / \mathrm{L}\right)$ and 51.67 percent had severe hyponatraemia $\left({ }_{\mathrm{p}} \mathrm{Na}<125 \mathrm{mmol} / \mathrm{L}\right)$. Intracranial disorders (stroke, encephalitis, meningitis, subarachnoid hemorrhage and intracranial neoplasm) comprised the commonest cause of hyponatraemia in the present study. They comprised 47.06 percent of hyponatraemic patients. Hepatic encephalopathy including fulminant hepatic failure, gastrointestinal disorders (acute gastroenteritis and peptic ulcer disease), chronic renal failure and ischaemic heart disease comprised 13.73, 11.76, 9.80 and 5.89 percent respectively. Diabetic ketoacidosis and hypoglycaemic shock comprised 3.92 percent each of the hyponatraemic patients. Congestive heart failure and acute repiratory distress syndrome comprised 1.96 percent each (Table I). Of the total 60 patients with acute confusional state including coma, 2 patients presented with hypoglycaemic shock. Of these, one had near normal plasma sodium level $(134.6 \mathrm{mmol} / \mathrm{L})$ and the rest one was moderately hyponatraemic $(127.8 \mathrm{mmol} / \mathrm{L})$. Vomiting and diarrhoea were responsible for hyponatraemia in gastrointestinal disorders. Of the total study population, $31.67,33.33$ and 35 percent presented with coma, stupor and drowsiness, respectively (Table II). In this study there were factors other than hyponatraemia responsible for clouding of consciousness. Intracranial disorders themselves contributed to the impairment of consciousness level. In this study, 9 patients had normal serum sodium level. Out of these 9 patients, 5 patients presented with stroke with clouding of consciousness. Out of 6 patients with gastrointestinal disorders presenting with acute confusional states had hyponatraemia. This group of patients recovered without any sequelae after slow correction of serum sodium level. Again, a patient with subarachnoid haemorrhage presenting with deep coma had severe hyponatraemia. The patient regained consciousness after slow correction of hyponatraemia with hypertonic saline. In the present study, severe hyponatraemia was present in 68.42 (Table III), 50.00 (Table À $1 / 2$ ) and 38.10 (Table IV) percent among the comatose, stuporous and drowsy patients respectively. So, the state of consciousness deteriorates as serum sodium level falls.

Table I

Distribution of various diseases presenting with hyponatraemia $(n=51)$

\begin{tabular}{lcc}
\hline Diseases & Number of patients & Percentage \\
\hline Intracranial disorders & 24 & 47.06 \\
Hepatic encephalopathy & 7 & 13.73 \\
Gastrointestinal disorders & 6 & 11.76 \\
Chronic renal failure & 5 & 9.80 \\
Ischaemic heart disease & 3 & 5.89 \\
Hypoglycaemic shock & 2 & 3.92 \\
Diabetic ketoacidosis & 2 & 3.92 \\
Congestive heart failure & 1 & 1.96 \\
Acute respiratory distress & 1 & 1.96 \\
Syndrome (ARDS) & & \\
\hline
\end{tabular}

\section{Table II}

Distribution of stages of acute confusion and coma $(n=60)$.

\begin{tabular}{lcc}
\hline Presentation & Number of patients & Percentage \\
\hline Coma & 19 & 31.67 \\
Stupor & 20 & 33.33 \\
Drowsiness & 21 & 35.00 \\
\hline
\end{tabular}


Table III

Distribution of comatose patients in various serum sodium levels $(n=19)$.

\begin{tabular}{lcc}
\hline $\begin{array}{l}\text { Serum sodium levels } \\
(\mathrm{mmol} / \mathrm{L})\end{array}$ & $\begin{array}{c}\text { Number of } \\
\text { patients }\end{array}$ & Percentage \\
\hline $136-144$ & 4 & 21.05 \\
$130-135.9$ & 2 & 10.53 \\
$125-129.9$ & 0 & 0.00 \\
$<125$ & 13 & 68.42 \\
\hline
\end{tabular}

Table IV

Distribution of stuporous patients according to various serum sodium levels $(n=20)$.

\begin{tabular}{lcc}
\hline $\begin{array}{l}\text { Serum sodium }(\mathrm{pNa}) \\
\text { levels }(\mathrm{mmol} / \mathrm{L})\end{array}$ & $\begin{array}{c}\text { Number of } \\
\text { patients }\end{array}$ & Percentage \\
\hline $136-144$ & 1 & 5.00 \\
$130-135.9$ & 5 & 25.00 \\
$125-129.9$ & 4 & 20.00 \\
$<125$ & 10 & 50.00 \\
\hline
\end{tabular}

Table V

Distribution of drowsy patients according to various serum sodium levels $(n=21)$.

\begin{tabular}{lcc}
\hline $\begin{array}{l}\text { Serum sodium }(\mathrm{pNa}) \\
\text { levels }(\mathrm{mmol} / \mathrm{L})\end{array}$ & $\begin{array}{c}\text { Number of } \\
\text { patients }\end{array}$ & Percentage \\
\hline $136-144$ & 4 & 19.05 \\
$130-135.9$ & 5 & 23.80 \\
$125-129.9$ & 4 & 19.05 \\
$<125$ & 8 & 38.10 \\
\hline
\end{tabular}

\section{Discussion:}

Hyponatraemia is the commonest electrolyte disorder and prevalence of it is quite common in patients with acute confusional states and coma. In this study, out of 60 patients with acute confusional states including coma, 51 (85\%) presented with hyponatraemnia. Of these, 20 percent had mild hyponatraemia ( $\mathrm{Na} 130-135.9 \mathrm{mmol} / \mathrm{L}), 13.33$ percent moderate ( $\left.{ }_{\mathrm{p}} \mathrm{Na} 125-129.9 \mathrm{mmol} / \mathrm{L}\right)$ and 51.67 percent had severe hyponatraemia $\left({ }_{\mathrm{p}} \mathrm{Na}<125 \mathrm{mmol} / \mathrm{L}\right) .{ }^{1}$ Gross et al. also showed hyponatraemia as the frequent electrelyte disorder in clinical medicine ${ }^{9}$. But in a study of 3000 patients carried out by Baylis, mild and severe hyponatraemia was prevalent in 10 and 1 percent of cases, respectively. In the percent of study, the study population consisted of patients with acute confusional states including coma, but the study of Baylis was on 3000 random hospital patiens. Intracranial diseases comprised the commonest (47.06) cause of hyponatraemia in the present study. Betjes and Koopmans in a study showed hyponatraemia as a frequent finding in the course of acute intracranial disease. ${ }^{6}$ This correlates well with the present study. SIADH was probably responsible for hyponatremia in intracranial disorders. ${ }^{10,11}$ Although serum antidiuretic hormone (ADH) and urinary sodium was not measured in our study due to unavailability of the test during that time. Among the hyponatraemic patients hepatic encepholopathy, gastrointestinal disorders, chronic renal failure and ischaemic heart diseases comprised 13.73, 11.76, 9.80 and 5.89 percent, respectively. Vomiting and diarrhoea were responsible for hyponatraemia in gastrointestinal disorders. Vomiting also contribute to hyponatraemia in ischaemic heart disease and chronic renal failure. Hyponatraemia in hetatic encaphalopathy has been well demonstrated in many a studies. ${ }^{12,13}$ Diabetic ketoacidosis and hypoglycaemic shock comprised 3.92 percent each of the hyponatraemic patients. Congestive heart failure due to hypertension and acute repiratory distress syndrome comprised 1.96 percent each. Out of 6 patients with gastrointestinal disorders presenting with acute confusional states, all had hyponatraemia. This group of patients recovered without any sequelae after slow correction of serum sodium level. ${ }^{14}$ Again, a patient with subrachnoid haemorrhage presenting with deep coma had severe hyponatraemia. The patient regained consciousness after slow correction of hyponatraemia with hypertonic saline. Recently earlier rapid infusion of $3 \% \mathrm{Nacl}$ solution had been advocated. ${ }^{15}$ This correlates with the study of Baylis who showed that symptoms of hyponatraemia depends on the absolute value of sodium as well as to the underlying cause ${ }^{1}$. Out of two patients presenting with hypoglycaemic coma one had moderate hyponatraemia $(127.8 \mathrm{~mol} / \mathrm{L})$. In the present study, severe hyponatraemia was present in 68.42, 50.00 and 38.10 percent among comatose, stuporous and drowsy patients, respectively. So, the state of consciousness deteriorates as serum sodium level falls. Earlier correction of it may prevent permanent brain disorder. ${ }^{16}$ Of course, although causes of acute confusion other than hyponatraemia could not be isolated in all the cases.

\section{Conclusions:}

Hyponatraemia is a common clinical problem in our day to day clinical practice. A patient may present with acute confusion including coma. A number of diseases, like intracranial disorders, including stroke and encephalitis, gastrointestinal disorders, cardiovascular diseases, respiratory diseases, renal diseases, hepatic and metabolic disorders may cause hyponatraemia. Many of these diseases are responsible for acute confusional states including coma; again, hyponatraemia itself may cause confusion including 
coma. With judicious correction of serum sodium level, patients may recover without any sequelae provided no irreversible cause of blurred consciousness.

\section{Conflict of interest: None.}

\section{References:}

1. Baylis PH. Hyponatraemia. Med Intern 1989;3:2620-3.

2. Usala RL, Fernandez SJ, Mete M, Cowen L, Shara NM.et al. Hyponatremia is allocated with increased ostepporosis and bone fractures in a large US health system population. $\mathrm{J}$ Clin Endocrinol Metab. 2015;100(8):3021-3031.

3. Nagler EV, Vanmassenhove J, Veer SN van der, Nistor L, Biesen WV, Webster AC et al. Diagnosis and treatment of hyponatremia: a systematic review of clinical practice guidelines and consensus statements. BMC Medicine 2014; $12: 231$.

4. Ellis SJ. Severe hyponatraemia: complication and treatment. QJM 1995;88:905-9.

5. Lee CT, Guo HR, Chen JB. Hyponatremia in the emergency department. Am J Emerg Med 2000;18:264-8.

6. Betjes MG, Koopmans RP. Hyponatremia in acute intracranial disorders: Cerebral salt wasting. Ned Tijdschr Geneeskd 2000; 144:553-6.

7. Bannister R. Disordes of the cerebral circulation. In: Brain and Bannister's clinical Neurology. 7th ed. Oxford: Oxford University Press, 1992:237-82.
8. Soupart A, Ngassa M, Decaux G. Therapeutic relowering of the serum sodium in a patient after excessive correction of hyponatremia, Clin Nephrol 1999;51:383-6.

9. Gross P, Wehrle R, Bussemaker E. Hyponatremia: pathophysiology, differential diagnosis and new aspects of treatment. Clin Nephrol 1996;46:273-6.

10. Liamis G, Elisa M. Syndrome of inappropriate antidiuresis associated with multiple sclerosis. J Neurol Sci 2000;172:3840.

11. Cho KC. Electrolyte and acid-base disorder. In: Papadakis MA, Mcphee SJ editors. Current medical diagnosis and treatment. 56th ed. New York: Lange Medical Books/ McGraw-Hill Book, Inc., 2017:884-912.

12. Sherlock S, Dooley J. Fulinant hepatic failure. In: Diseases of the liver and biliary system. 9th ed. Edinburgh: Blackwell Scientific Publications, 1993:102-13.

13. Mamun AA, Mridha MJU, Alam K, Asraf MS, Ferdoushi S, Majid F. Correlation between the serum sodium and the severity of liver disease in cirrhotic patients. Bangladesh Med J. 2013;42(3):73-77.

14. Nagaratnam N, Icao E, Peric H. Abnormal movements associated with severe hyponatremia. Postgrad med J 1997;73:503-4.

15. Adrogue HJ, Madias N Am J Kidney Dis. 2014; 64(5):681684.

16. Chamberlain L. Hyponatremia Caused by Polydipsa. Critical Care Nurse, April 2012; 32:e1-e7. 